\title{
Hypotensive and Bradycardic Effects of $d l$-Tetrahydropalmatine Mediated by Decrease in Hypothalamic Serotonin Release in the Rat
}

\author{
Fu-Yu Chueh ${ }^{1}$, Ming-Tsuen Hsieh ${ }^{1}$, Chieh-Fu Chen ${ }^{2}$ and Mao-Tsun Lin ${ }^{3, *}$ \\ 'Institute of Chinese Pharmaceutical Sciences, China Medical College, Taichung, Taiwan \\ ${ }^{2}$ National Research Institute of Chinese Medicine, Taipei Hsien, Taiwan \\ ${ }^{3}$ Department of Physiology, National Cheng Kung University Medical College, Tainan, Taiwan
}

Received March 15, 1995 Accepted August 22, 1995

\begin{abstract}
In anesthetized rats, intravenous administration of $d$-tetrahydropalmatine ( $d l$-THP, $1-10$ $\mathrm{mg} / \mathrm{kg}$ ) elicited proportional hypotension, bradycardia and decreases in hypothalamic serotonin $(5-\mathrm{HT})$ release (measured by carbon-fiber electrodes in combination with voltammetry). In addition, postsynaptic blockade of $5-\mathrm{HT}_{2}$ receptors with cyproheptadine $(2-5 \mathrm{mg} / \mathrm{kg}, \mathrm{i} . v$. $)$ or ketanserin $(2-5 \mathrm{mg} / \mathrm{kg}$, i.v.) produced both hypotension and bradycardia, while stimulation of $5-\mathrm{HT}_{2}$ receptors with 1-(2,5-dimethoxy4-iodophenyl)-2-aminopropane (DOI) $(10-250 \mathrm{mg} / \mathrm{kg}$, i.v.) produced both hypertension and tachycardia. The $d l$-THP-induced hypotension and bradycardia could be reversed by DOI treatment. The data indicate that $d l$-THP decreases both arterial pressure and heart rate through a serotonergic release process in the hypothalamus.
\end{abstract}

Keywords: $d l$-Tetrahydropalmatine, Blood pressure, Serotonin

There is accumulating evidence indicating that seroto$\operatorname{nin}(5-\mathrm{HT})$ has an important regulatory role in the central control of cardiovascular function (1). The central serotonergic system acts through the sympathetic and parasympathetic pathway activity to affect the vasculature and heart. Activation of a bulbospinal projection that descends from the ventrolateral medulla and terminates in the intermediolateral column evokes a pressor response (2). Activation of one important ascending 5HT pathway innervating the hypothalamus also causes an increase in blood pressure (3). Other studies have shown that $d l$-tetrahydropalmatine ( $d l$-THP), an active principle isolated from Corydalis, possesses analgesic, sedative, tranquilizing and hypnotic actions (4-6). It has been shown that $d l$-THP depletes the levels of three neurotransmitters in the central nervous system: 5-HT, dopamine and norepinephrine (7). This raises the possibility that $d l$-THP acts through the hypothalamic serotonergic mechanism to influence blood pressure. Therefore, the present study has attempted to assess the effects of $d l$ THP on both the hypothalamic 5-HT release measured by in vivo voltammetry, blood pressure and heart rate in rats. In addition, the cardiovascular responses by $d l$-THP

* To whom correspondence should be addressed. were compared with those of DOI (a $5-\mathrm{HT}_{2}$-receptor agonist), ketanserin and cyprohetadine (two 5- $\mathrm{HT}_{2}$-receptor antagonists).

Male Sprague-Dawley rats $(250-300 \mathrm{~g})$ were used in the present study. Upon receipt from the supplier (Animal Resource Center, National Cheng Kung University Medical College, Tainan, Taiwan), the animals were housed in a temperature-regulated $\left(22 \pm 1{ }^{\circ} \mathrm{C}\right)$ room on a 12: 12-hr light-dark cycle with food and water provided ad libitum for at least 2 weeks before the experiments. The light was turned on at 6:00 and turned off at 18:00.

A multiple carbon fiber $(28 \mu \mathrm{m}$ in diamter; Avco, Lowell, MA, USA) was inserted into a pulled glass micropipette (20-25 $\mathrm{mm}$ in length). The tip was cut, and then the carbon fiber was pushed out of the pipette tip. Electrical contact with the fiber was made using silver paste. The tip and blunt and of the pipette were sealed with cyanoacrylate adhesive (super glue). The entire surface of the pyrolytic carbon fiber was 12 -mm-thick and $200 \pm 25$-mm-long. To improve the sensitivity and selectivity of carbon fiber electrodes for 5-HT, the electrodes were electrically pretreated as described previously (8). This treatment consisted of a direct current applied in two stages: $2.2 \mathrm{~V}$ for $30 \mathrm{sec}$ in $0.1 \mathrm{M} \mathrm{H}_{2} \mathrm{SO}_{4}$ and $2.2 \mathrm{~V}$ for 30 sec in $1 \mathrm{~N} \mathrm{HCl}$. The carbon fiber electrode was washed 
with distilled water. The tip of the carbon fiber electrode was immersed into a nafion drop $(10 \mathrm{ml}$ of a $5 \%$ solution; Aldrich Chemical, Milwaukee, WI, USA) four times. The nafion-coated electrode was then dried at $60^{\circ} \mathrm{C}$ for $20 \mathrm{sec}$ and used immediately for in vitro followed by in vivo experiments. Differential pulse amperometry was performed in vitro and in vivo with a Biopulse apparatus (Solea Tacussel, France) using the following scan parameters: imposed initial potential $=-100 \mathrm{mV}$, imposed final potential $=+260 \mathrm{mV}$, pulse cycle $=2 \mathrm{sec}$, prepulse $=80 \mathrm{msec}$, measuring pulse $=40 \mathrm{msec}$ and measuring potential $=40 \mathrm{mV}$. The sensitivity of the nafioncoated carbon fiber electrode to 5-HT in the concentration range of $200-1000 \mathrm{nM}$ was determined using differential pulse amperometry in a temperature-controlled $\left(37^{\circ} \mathrm{C}\right)$ water bath. Phosphate-buffered saline $(0.1$ $\mathrm{M}, \mathrm{pH}$ 7.4) was used as the blank and solvent for the test solutions. To determine the sensitivity of the nafion-coated electrodes $($ resistance $=200 \Omega$, capacitance $=0.0056 \mu \mathrm{F})$ for 5-HT over 5-hydroxyindoleacetic acid (5-HIAA), the ratio of the sensitivity of 5-HT to 5-HIAA was calculated. Our electrodes were 200 times more sensitive to 5-HT than to 5-HIAA. Our electrodes are insensitive to dopamine. The animals were anesthetized with urethane (1.4 $\mathrm{g} / \mathrm{kg}$, i.p.), held in a stereotaxic frame and implanted unilaterally with a nafion-coated carbon fiber electrode in the anteior hypothalamus using the coordinates of Paxinos and Watson (9). Auxiliary (silver wire) and reference $(\mathrm{Ag} / \mathrm{AgCl})$ electrodes were placed on the dura surface of the parietal skull. Differential pulse voltammograms were then recorded automatically every $2 \mathrm{sec}$. After concluding the experiments, $4 \mathrm{~mA}$ anodal d.c. was passed through the working electrodes for $10 \mathrm{sec}$ and the resultant lesions were located to identify the actual electrode site. All electrode placements were in the region of the hypothalamus as verified by standard histological procedures. Animals were perfused with physiological saline, followed by $10 \%$ formalin. The brains were removed, sliced on a freezing microtome and stained with formyl thionine.

A fine catheter was inserted into the femoral artery of rats. The catheter was connected via a Statham blood pressure transducer to a Gould four-channel polygraph for recording mean arterial and pulsatile blood pressure. The catheter was also used for blood sampling. Both the heart rate and blood gases were measured. Another polyethylene catheter was inserted into the femoral vein to inject drugs.

Drugs, administered intravenously, included $d l$-tetrahydropalmatine ( $d l$-THP) (given to us by the Institute of Applied Chemistry of Providence College of Arts and Sciences, Taichung, Taiwan), 1-(2,5-dimethoxy-4-iodophenyl)-2-aminopropane (DOI) (RBI, Natick, MA, USA), cyproheptadine (RBI) and ketanserin (RBI). $d l$ -
Table 1. Maximal changes in mean arterial pressure (MAP), heart rate (HR) and hypothalamic 5-HT release produced by intravenous injection of $d l$-THP in anesthetized rats

\begin{tabular}{cccc}
\hline $\begin{array}{c}\text { Treatment } \\
(\mathrm{mg} / \mathrm{kg})\end{array}$ & $\begin{array}{c}\Delta \mathrm{MAP} \\
(\mathrm{mmHg})\end{array}$ & $\begin{array}{c}\Delta \mathrm{HR} \\
\text { (beats/min) }\end{array}$ & $\begin{array}{c}\Delta \text { Hypothalamic 5-HT release } \\
\left(\%_{0} \text { baseline }\right)\end{array}$ \\
\hline Vehicle & $4 \pm 1$ & $-3 \pm 1$ & $4 \pm 2$ \\
1 & $-11 \pm 3^{*}$ & $-11 \pm 2^{*}$ & $-21 \pm 4^{*}$ \\
5 & $-21 \pm 3^{*}$ & $-38 \pm 5^{*}$ & $-39 \pm 5^{*}$ \\
10 & $-38 \pm 4^{*}$ & $-43 \pm 7^{*}$ & $-52 \pm 7^{*}$ \\
\hline
\end{tabular}

Values are means \pm S.E.M. of 8 rats. $A$, difference between control values before and $10 \mathrm{~min}$ after the start of $d l$-THP injection. ${ }^{*} \mathrm{P}<$ 0.05 , significantly different from control values (vehicle), ANOVA.

THP was dissolved in a stock solution made of $10 \%(\mathrm{v} / \mathrm{v})$ phosphoric acid plus distilled water $(1: 9)$. The $\mathrm{pH}$ value of the $d l$-THP solution was adjusted to 4.5 with $1 \mathrm{~N}$ $\mathrm{NaOH}$.

The numerical values cited in the text refer to the mean \pm S.E.M. The mean arterial pressure was calculated as the diastolic pressure plus one-third of the pulse pressure (systolic-diastolic pressure). Student's $t$-test was used when only two groups were compared. ANOVA was used for factorial experiments and Dunn's procedure for post hoc multiple comparisons among means was used. The criterion for statistical significance was set at the 0.05 level.

Table 1 summarizes the response of cardiovascular parameters and hypothalamic 5-HT release produced by intravenous administration of vehicle or $d l$-THP in rats under urethane anesthesia. Administration of $d l$-THP $(1-10 \mathrm{mg} / \mathrm{kg})$, but not vehicle, produced a dose-related fall in either mean arterial pressure, heart rate or hypothalamic 5-HT release. A typical example for this kind of response is shown in Fig. 1. For a dose of 10 $\mathrm{mg} / \mathrm{kg}$ of $d l$-THP, either the mean arterial pressure, heart rate or hypothalamic 5-HT release fell immediately after $d l$-THP injection and did not return to preinjection level even after $60 \mathrm{~min}$. $d l$-THP treatment produced an insignificant change in either $\mathrm{Pa}_{\mathrm{CO}_{2}}, \mathrm{~Pa}_{\mathrm{O}_{2}}$ or $\mathrm{pH}$ (data are not shown here).

Table 2 summarizes the response of cardiovascular parameters produced by intravenous administration of DOI, cyproheptadine or ketanserin in rats. Intravenous administration of cyproheptadine ( 2 and $5 \mathrm{mg} / \mathrm{kg}$ ) or ketanserin ( 2 and $5 \mathrm{mg} / \mathrm{kg}$ ) caused a decrease in both mean arterial pressure and heart rate. In contrast, intravenous injection of DOI $(10-250 \mu \mathrm{g} / \mathrm{kg})$ caused an increase in both mean arterial pressure and heart rate. Furthermore, the dl-THP-induced hypotension and bradycardia were reversed by DOI treatment.

The present results demonstrate that intravenous injection of $d l$-THP elicited a proportional decrease in 

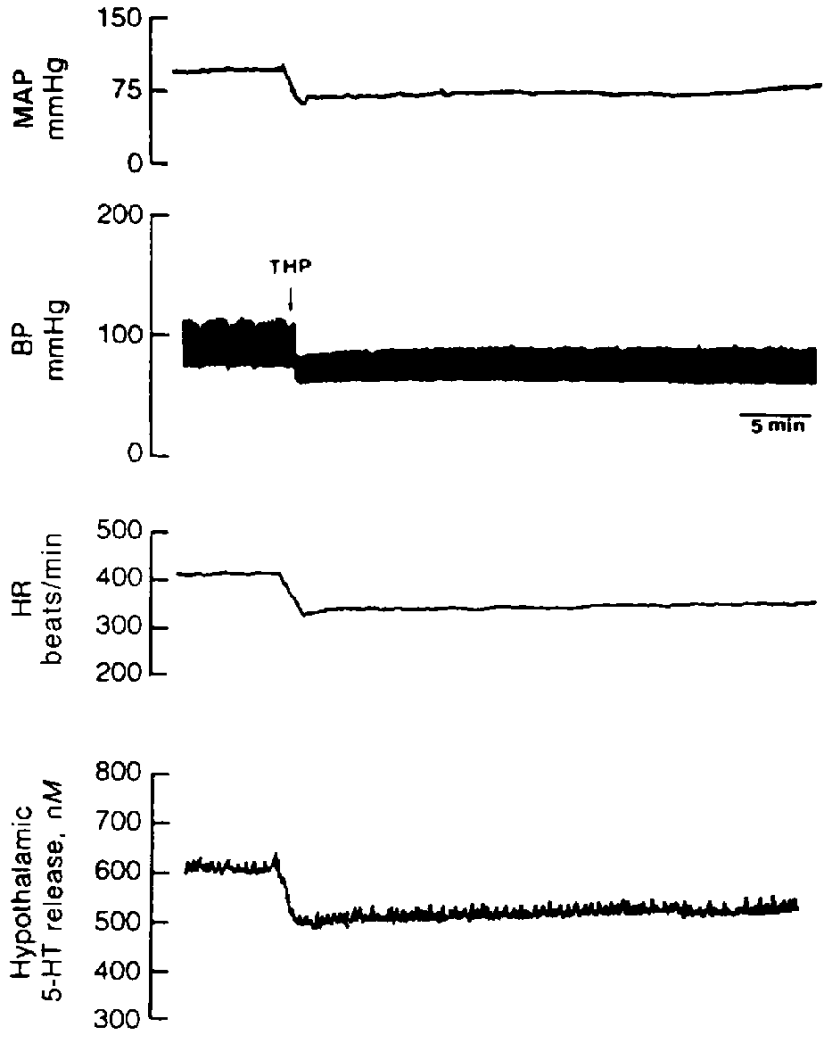

Fig. 1. The time course of mean arterial pressure (MAP), pulsatile blood pressure (BP), heart rate (HR) and hypothalamic serotonin (5-HT) release produced by intravenous administration of $d l$-THP $(10 \mathrm{mg} / \mathrm{kg})$ in an anesthetized rat.

either the mean arterial pressure or heart rate, which could be mimicked by intravenous injection of $5-\mathrm{HT}_{2}$ receptor antagonists such as cyproheptadine and ketanserin in rats. The 5 - $\mathrm{HT}_{2}$-receptor agonist DOI, in addition to producing hypertension and tachycardia, attenuated the $d l$-THP-induced hypotension and bradycardia in rats, when given intravenously. In addition, $d l$-THP administration caused a proportional decrease in the endogenous release of 5-HT in the hypothalamus. These results suggest that $d l$-THP decreases the hypothalamic 5-HT release and results in a decrease in either the mean arterial pressure or the heart rate in rats. Our recent results also showed that the hypotension induced by $d l$ THP was attenuated by pretreatment of animals with spinal transection, whereas the bradycardia induced by $d l$-THP was attenuated by bilateral vagotomy $(10)$. These observations imply that the $d l$-THP-induced hypotension are attributable to inhibition of sympathetic efferent activity, while the $d l$-THP-induced bradycardia are attributable to activation of parasympathetic efferent activity.

The proposed contention is supported by many previous findings. For example, intracerebral injection of 5 -
Table 2. Maximal changes in mean arterial pressure (MAP) and heart the (HR) produced by intravenous injection of DOI, cyproheptadine or $d l$-THP in anesthetized rats

\begin{tabular}{|c|c|c|}
\hline \multirow[b]{2}{*}{ Treatment } & \multicolumn{2}{|c|}{ Parameter measured } \\
\hline & $\begin{array}{c}1 \mathrm{MAP} \\
(\mathrm{mmHg})\end{array}$ & $\begin{array}{c}\mathrm{JHR} \\
\text { (beats } / \mathrm{min} \text { ) }\end{array}$ \\
\hline $0.9 \%$ saline, i.v. & $7 \pm 3$ & $4 \pm 2$ \\
\hline DOI, $10 \mu \mathrm{g} / \mathrm{kg}$, i.v. & $14 \pm 1^{*}$ & $15 \pm 2^{*}$ \\
\hline DOI, $50 \mu \mathrm{g} / \mathrm{kg}$, i.v. & $30 \pm 5^{*}$ & $30 \pm 8^{*}$ \\
\hline DOI, $250 \mu \mathrm{g} / \mathrm{kg}$, i.v. & $51+9 *$ & $52 \pm 8^{*}$ \\
\hline Cyproheptadine, $2 \mathrm{mg} / \mathrm{kg}$, i.v. & $-24 \pm 3^{*}$ & $-66 \pm 13^{*}$ \\
\hline Cyproheptadine, $5 \mathrm{mg} / \mathrm{kg}$, i.v. & $-46 \pm 3^{*}$ & $-158 \pm 24^{*}$ \\
\hline Ketanserin, $2 \mathrm{mg} / \mathrm{kg}$, i.v. & $-25 \pm 4^{*}$ & $-63 \pm 7^{*}$ \\
\hline Ketanserin, $5 \mathrm{mg} / \mathrm{kg}$, i.v. & $-51 \pm 5^{*}$ & $-164 \pm 35^{*}$ \\
\hline $0.9 \%$ saline $+d /$-THP, $5 \mathrm{mg} / \mathrm{kg}$ & $-25 \pm 4$ & $-32 \pm 6$ \\
\hline $\mathrm{DOl}, 250 \mu \mathrm{g} / \mathrm{kg}+d l-\mathrm{THP}, 5 \mathrm{mg} / \mathrm{kg}$ & $6 \pm 3^{\mu}$ & $38 \pm 11^{4}$ \\
\hline
\end{tabular}

Values are means \pm S.E.M. of 6 rats. $\mathcal{~}$, difference between control values before and $10 \mathrm{~min}$ after injection of drugs or saline. ${ }^{*} \mathrm{P}<0.05$, significantly different from control values (saline injection), ANOVA. ${ }^{4} \mathbf{P}<0.05$, significantly different from control values (saline $+d l$-THP), Student's $t$-test.

$\mathrm{HT}$ or $5-\mathrm{HT}_{2}$-receptor agonists resulted in an increase in sympathetic outflow to the heart and rise in arterial blood pressure $(2,11,12)$, while intracerebral injection of ketanserin decreased arterial blood pressure (13). The pressor effects of raphe nuclei stimulation were also shown to be abolished by transection to the midbrain, confirming the ascending projection pathway (14). Transection caudal to the midbrain also abolished these pressor responses and demonstrated that a relay descending pathway must be activated for sympathetic activity to be modified. The present results showed that $d l$-THP decreased the serotonin release in the hypothalamus and shared with the $5-\mathrm{HT}_{2}$ antagonists the same depressor action. These results suggest that the $d l$-THP-induced hypotension and bradycardia may be due to alteration in the 5-HT releasing process in the hypothalamus. However, in additional to central action, $d l$-THP may possess peripheral action. It was found that in pitched rats, $l$-THP administered into the common carotid artery reduced the 5-HT (i.v.)-induced increase in diastolic pressure (15). The contraction of the isolated blood vessels induced by 5-HT, norepinephrine or $\mathrm{KCl}$ was also antagonized by $l$-THP. In order to ascertain the possible site of action of $d l$-THP on the 5-HT synapse in the central nervous system, future experiments should be carried out to assess the effects of intracerebral injection of a watersoluble form of $d l$-THP on cardiovascular responses. The $d l$-THP used in the present study was dissolved in phosphoric acid and therefore not suitable for central injection. 
Acknowledgments

The work reported here was supported by grants from the National Science Council (Taipei, Taiwan) (NSC 81-0420-B039-03) and National Institute of Health (Taipei, Taiwan) (DOH 84-CM008).

\section{REFERENCES}

1 Gothert $\mathrm{M}$ and Kolassa $\mathrm{N}$ : $5-\mathrm{HT}_{1 \mathrm{~A}}$ receptors in the brain: a subtype of serotonin receptors involved in blood pressure reduction. J Cardiovasc Pharmacol 7, s1-s93 (1990)

2 Minson J, Chalmers J, Drolet G, Kapoor V, Llewellyn-Smith I, Mills $E$, Morris $M$ and Pilowsky P: Central serotonergic mechanisms in cardiovascular regulation. Cardiovasc Drugs Ther 4, 27-32 (1990)

3 Kuhn DM, William A, Wolf BA and Lovenberg W: Review of the role of the central serotonergic neuronal system in blood pressure regulation. Hypertension 2, 243-255 (1980)

4 Dharmananda S: The story of Jin Bu Huan. Herbal Gram 31, 28-31 (1994)

5 Hsu B and Kin KC: Pharmacology of tetrahydropalmatine and its analogs. Arch Int Pharmacodyn Ther 139, 318- 327 (1962)

6 Hsu B and Kin KC: Further studies on the pharmacology of tetrahydropalmatine and its analogs. Int $\mathbf{J}$ Neuropharmacol 2 , 283-290 (1964)

7 Liu GQ, Algeris A and Garattini S: $d l$-Tetrahydropalmatine as monoamine depletor. Arch Int Pharmacodyn Ther 258, 39-50
(1982)

8 Lin MT and Yang JJ: Stimulation of the nigrostriatal dopamine system produces hypertension and tachycardia in rats. Am J Physiol 226, H2489- H2496 (1994)

9 Paxinos $\mathrm{G}$ and Watson C: The Rat Brain in Stereotaxic Coordinates. Academic Press, New York (1982)

10 Chueh FY, Hsieh MT, Chen CF and Lin MT: dl-Tetrahydropalmatine-produced hypotension and bradycardia in rats through the inhibition of central nervous dopaminergic mechanisms. Pharmacology (in press)

11 Gillis RA, Mandal AK, Hernandez YM, Norman WP, Dretchen KE and Travagli RA: Brainstem serotonin receptor subtypes and cardiovascular control. Adv Biosci 85, 361 - 381 (1992)

12 Kristic $M$ and Djurlpvic D: Analysis of cardiovascular response to central administration of 5-hydroxytryptamine in rats. Neuropharmacology 19, 455-463 (1980)

13 Mandal AK, Kellar KJ, Norman WP and Gillis RA: Stimulation of serotonin 2 receptors in the ventrolateral medulla of the cat results in nonuniform increases in sympathetic outflow. Circ Res 67, 1267-1280 (1990)

14 Kuhn DM, Wolf WA and Lovenberg W: Pressor effects of electrical stimulation of the dorsal and median raphe nuclei in anesthetized rats. J Pharmacol Exp Ther 214, $403-409$ (1980)

15 Zhao GJ, Ren SL, Wu S and Yu LS: Effect of $l$-THP on density of blood vessels induced by 5-hydroxytryptamine. Chin J Pharmacol Toxicol 2, 247-251 (1988) 